\title{
DAMPAK PENANGKAPAN TERHADAP STRUKTUR DAN TINGKAT TROFIK HASIL TANGKAPAN IKAN DI PERAIRAN MALUKU TENGGARA
}

\section{(IMPACT OF FISHING ON STRUCTURE AND TROPHIC LEVEL OF THE FISH CATCH IN SOUTHEAST MALUKU WATER)}

\author{
Erna Almohdar ${ }^{1,2}$, Mulyono S Baskoro³, Roza Yusfiandayani ${ }^{3}$, Am Azbas Taurusman ${ }^{3}$ \\ ${ }^{1}$ Corresponding author \\ ${ }^{2}$ Politeknik Perikanan Negeri Tual, Ambon \\ ${ }^{3}$ Departemen Pemanfaatan Sumberdaya Perikanan \\ Fakultas Perikanan dan Ilmu Kelautan, Institut Pertanian Bogor \\ E-mail: almohdarerna@yahoo.co.id
}

\begin{abstract}
Fishing has adirect and indirect impacton coastal and marine ecosystems. The fishing activity has been intensively conducted in the Southeast Maluku district and potentially impact the fish resources negatively. Fishermen generally catch fish using gill nets, lift net and hook line. This study aims to analyze the impact of fishing on ecosystem structure and trophic level of the catch by each fishing gear. An experimental fishing was conducted for the sampling strategy by means of fishing operations using gill net, lift net and hook. line. Data were analyses for parameters of feeding habits, length-weight relationships, and trophic level of the catch. The results showed that trophic level of fish taken by lift net and gill netranged from 2.9 to 3.7 which grouped as TL3, dominated by species of omnivorous feeding habit (zooplankton). The gill net has dominantly caught the group of fish at trophic level 5 (4.0-4.5). The average total length of the dominant fish targets were D. Russeli $(18.2 \pm 12.5 \mathrm{~cm})$, Sardinella longiceps $(19.8 \pm 13.3 \mathrm{~cm}), \quad$ S.crumenopthalmus $(21.9 \pm 14.2 \mathrm{~cm})$, Letbrinus lentian $(20.1 \pm 13.3 \mathrm{~cm})$ and Upeneus mulocensis $(21.9 \pm 14.2 \mathrm{~cm})$. For the average weight ofthe main catches were D. Russeli $(90 \pm 35 \mathrm{~g})$, Sardinella longiceps (81 $28 \mathrm{~g})$, S.crumenopthalmus $(89 \pm 40 \mathrm{~g})$, Letbrinus lentjan $(92 \pm 28 \mathrm{~g})$ and Upeneus mulocensis $(90 \pm 30 \mathrm{~g})$. The catch by lift net, gillnet and hook line indicates unbalance exploitation of the natural food chain. TL groups 3 and 5 was more dominantly exploited. It is theoretically potentially impacting the ecological balance of fish resources in these habitats. Furthermore, the lift net and gill net have greater impact on sustainability of fish resources than hook line due to both the earlier dominantly exploited unallowable catch sizes (juvenile) of the fish target.
\end{abstract}

Keywords: Fishing impact, trophic level of catch, feeding habits, Southeast Maluku

\section{ABSTRAK}

Penangkapan ikan memberikan dampak langsung dan tidak langsung terhadap ekosistem perairan. Penangkapan ikan yang dilakukan nelayan di perairan Maluku Tenggara terhadap ikan cukup intensif. Nelayan umumnya menangkap ikan menggunakan jaring insang (gillnet), bagan dan pancing. Penelitian ini bertujuan menganalisis dampak penangkapan terhadap ekosistem, yakni struktur komunitas dan tingkat trofik hasil tangkapan berdasarkan alat tangkap. Pengambilan sampel ikan dilakukan dengan metode experimental fishing, yaitu berupa operasi penangkapan ikan menggunakan alat tangkap jaring insang (gillnet), bagan dan pancing di lokasi studi. Analisis data meliputi parameter kebiasaan makan hubungan panjang berat ikan, dan tingkat trofik hasil tangkapan. Hasil penelitian menunjukan tingkat trofik ikan pada alat tangkap bagan dan jaring berkisar 2,9 - 3,7 dan berada pada pengelompokan tingkat trofik (TL3) yakni didominasi oleh jenis omnivora yang cenderung pemakan hewan (zooplankton). Alat tangkap pancing berkisar 4,0 - 4,5 berada pada TL5 dan didominasi oleh jenis karnivora yang cenderung pemakan ikan dan cephalopoda. Ukuran rata-rata panjang total jenis ikan hasil tangkapan yang dominan menurut alat tangkap adalah ikan layang $(18,2 \pm 12,5 \mathrm{~cm})$, ikan lemuru $(19,8 \pm 13,3 \mathrm{~cm})$, ikan selar $(21,9 \pm 14,2 \mathrm{~cm})$, ikan lencam $(20,1 \pm 13,3 \mathrm{~cm})$ dan ikan biji nangka $(21,9 \pm 14,2 \mathrm{~cm})$. Berat rata-rata hasil tangkapan utama adalah ikan layang ( $90 \pm 35 \mathrm{gr})$, ikan lemuru $(81 \pm 28$ gr), ikan selar (89 \pm

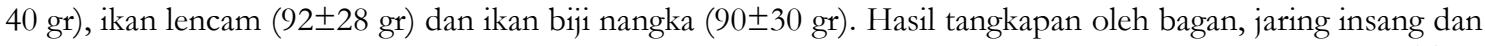
pancing mengindikasikan bahwa terjadi eksploitasi yang tidak seimbang pada rantai makanan. Kelompok TL 3 dan 5 lebih dominan dieksploitasi. Hal ini secara teoritis berpotensi merusak keseimbangan ekologis sumberdaya ikan di habitat tersebut. Alat tangkap bagan dan jaring mempunyai dampak lebih besar terhadap keberlanjutan sumberdaya ikan dibandingkan dengan alat tangkap pancing (TL5), karena kedua alat tangkap tersebut cenderung lebih eksploitatif pada ukuran ikan yang belum layak tangkap.

Kata kunci: Dampak penangkapan ikan, tingkat trofik hasil tangkapan, kebiasaan makan, Maluku Tenggara 


\section{PENDAHULUAN}

Kegiatan penangkapan sangat potensial berpengaruh pada semua tingkatan trofik dalam ekosistem. Dengan demikian pendekatan tingkat trofik dapat digunakan untuk mengevaluasi kesehatan dan kondisi ekosistem, sehingga merupakan mata rantai awal yang penting dipertimbangkan untuk menjaga keberlanjutan sumberdaya perikanan. Penangkapan yang dilakukan nelayan cukup intensif. Nelayan di perairan Maluku Tenggara umumnya menangkap ikan menggunakan jaring insang hanyut (gill-net), bagan dan pancing, yang dioperasikan di perairan sehingga diperlukan suatu upaya pengelolaan yang baik, berbasis pada informasi biologi, ekologi, populasi dan aspek lain yang berkaitan dengan pelestarian sumberdaya ikan. Dalam melakukan penangkapan ikan diperlukan berbagai informasi yang berkaitan dengan ikan seperti pertumbuhan, reproduksi, kebiasaan makanan serta kondisi habitat dimana ikan tersebut ditemukan.

Ekosistem laut saat ini telah mengalami penurunan kondisi alaminya, baik keragaman spesies maupun biomassanya (Stergiou et al, 2007). Tingkatan trofik menggambarkan tahapan transfer material atau energi dari setiap tingkat atau kelompok ke tingkat berikutnya, yang dimulai dengan produsen primer, konsumen primer (herbivora), kemudian sekunder, tersier, dan diakhiri dengan predator puncak. Pada dasarnya tingkat trofik (trophic level) merupakan urutan tingkat pemanfaatan pakan atau material dan energi seperti yang tergambarkan oleh rantai makanan (food chain).

Belum optimalnya pemanfaatan tersebut disebabkan beberapa faktor antara lain minimnya informasi tentang sumbardaya ikan, sehingga kegiatan penangkapan berdampak pada sruktur ikan target dan kerusakan habitat. Untuk mengetahui struktur sumberdaya ikan dan hubungannya dengan kegiatan penangkapan diperlukan suatu indikator berkelanjutan. Salah satu indikator yang digunakan adalah tingkat trofik hasil tangkapan, sehingga informasi perubahan tingkat trofik dalam rantai makanan pada ekosistem perairan diharapkan menjadi salah satu indikator yang penting bagi keberlanjutan kegiatan penangkapan pada suatu daerah penang- kapan ikan, khususnya di perairan Maluku Tenggara. Tujuan penelitian ini adalah: (1) Menganalisis dampak penangkapan terhadap keseimbangan ekosistem perairan di Desa Selayar dan (2) Menganalisis struktur komunitas dan tingkat trofik hasil tangkapan berdasarkan alat tangkap.

\section{METODE PENELITIAN}

\subsection{Waktu Penelitian}

Penelitian dilakukan di perairan Kabupaten Maluku Tenggara selama 6 bulan dari bulan Januari sampai Juli 2013. Analisis sampel dilakukan di Laboratorium Hidrobiologi Politeknik Perikanan Negeri Tual. Survei lapangan dilakukan di wilayah penangkapan ikan yaitu Desa Selayar. Lokasi penelitian dapat dilihat pada Gambar 1.

\subsection{Metode Pengumpulan Data}

Penelitian ini menggunakan metode experimental fishing, yaitu berupa operasi penangkapan ikan menggunakan alat tangkap jaring insang (gillnet), bagan dan pancing. Data primer berupa hasil tangkapan ikan yang diperoleh dari hasil pengamatan langsung (pengukuran morfologi dan pengukuran hasil tangkapan), hasil wawancara dengan nelayan, hasil pengisian kuesioner oleh responden. Sedangkan data sekunder diperoleh dari dinas dan instansi terkait serta literatur yang relevan.

Analisis makanan meliputi jenis dan jumlah makanan, dilakukan dengan mengambil sebagian makanan dari lambung yang diencerkan dan diamati menggunakan mikroskop dengan pembesaran $5 x 1$ serta menggunakan metode sensus sebanyak 3 kali ulangan. Lambung dipisahkan dari organ lain kemudian diukur panjang dan beratnya, bagian ujung dari lambung diikat agar makanan yang ada di dalamnya tidak keluar, kemudian lambung diawetkan dengan formalin $10 \%$ untuk perhitungan analisis makanan ikan di laboratorium. Saluran percernaan dibersihkan dari formalin kemudian isi lambung dipisahkan dan diukur volume dan beratnya. Isi lambung diencerkan dengan aquades sebanyak 3-5 $\mathrm{ml}$. 


\subsection{Analisis Data}

\subsubsection{Analisis Panjang dan Berat Ikan}

Panjang dan berat ikan hasil tangkapan utama setiap alat tangkap diukur, kemudian dianalisis hubungannya menggunakan rumus umum (Effendie, 1997) sebagai berikut:

$$
\mathrm{W}=\mathrm{a} \mathrm{L} \mathrm{b}
$$

Dimana: $\mathrm{W}=$ Berat, $\mathrm{L}=$ Panjang, $\mathrm{a}=$ Intersep (perpotongan kurva hubungan panjang dan berat dengan sumbu y), dan $\mathrm{b}=$ Penduga pola pertumbuhan panjang dan berat. Jika dilinierkan melalui transformasi logaritma, maka diperoleh persamaan sebagai berikut : $\mathrm{Ln} \mathrm{W}=\mathrm{Ln}$ a + b Ln L. Untuk mendapatkan parameter a dan b, digunakan analisis regresi dengan $\ln \mathrm{W}$ sebagai y dan Ln L sebagai $\mathrm{x}$.

\subsubsection{Analisis Isi Lambung Ikan}

Analisis isi lambung untuk mengetahui persentase konsumsi makanan ikan. Penentuan kebiasaan makanan menggunakan Indeks Bagian Terbesar (Natarajan dan Jhingran, 1961 dalam Effendie, 1979) yaitu:

Keterangan:

$$
\mathrm{I}_{\mathrm{i}}=\frac{\mathrm{Vi} \times \mathrm{Oi}}{\sum(\mathrm{Vi} \times \mathrm{Oi})} \times 100
$$

$\mathrm{V}_{\mathrm{i}}$ : persentase volume satu macam makanan

$\mathrm{O}_{\mathrm{i}}$ : persentase frekuensi kejadian satu macam makanan

$\mathrm{IP}_{\mathrm{i}}$ : indeks bagian terbesar

$\Sigma(\mathrm{Vi}$ x Oi) : jumlah Vi x Oi dari semua macam makanan

\subsubsection{Analisis Tingkat Trofik}

Analisis tingkat trofik (trophic level) atau jenjang rantai makanan digunakan untuk melihat dampak penangkapan terhadap komunitas ikan di perairan. Rata-rata trofik level hasil tangkapan pada setiap alat tangkap dihitung dengan rumus sebagai berikut (McClanahan dan Mangi, 2004):

$$
T L=\sum_{i=1}^{p} \frac{P i \times \text { Trofik }_{\mathrm{i}}}{\sum P i}
$$

Keterangan:

TL : Rata-rata tingkat trofik

$\mathrm{Pi}$ : Fraksi makanan ke-i

$\mathrm{Ti}$ : Tingkat trofik makanan ke-i

\section{HASIL DAN PEMBAHASAN}

\subsection{Komposisi hasil tangkapan}

Selama penelitian jenis ikan yang tertangkap di bulan Maret sampai April 2013 berjumlah 1.261 ekor yang terdiri dari 5 spesies. Hasil tangkapan diambil secara acak pada masing-masing alat tangkap bagan, jaring insang dan pancing sebanyak 50 ekor. Berat total hasil tangkapan mencapai 151547 gr atau $151,54 \mathrm{~kg}$. Komposisi ikan hasil tangkapan dominan di perairan Desa Selayar Kabupaten Maluku Tenggara, diperoleh menurut musim penangkapannya yaitu pada musim paceklik diwakili hasil tangkapan pada bulan April dan pada musim puncak diwakili hasil tangkapan pada bulan Maret. Hasil tangkapan tertinggi terdapat pada bulan Maret, perbandingan hasil tangkapan dapat dilihat pada Gambar 2.

Data hasil tangkapan diuji dengan metode statistik parametrik menggunakan Uji-F (ANOVA) yang digunakan untuk mengetahui perbandingan hasil tangkapan setiap bulan dan hasilnya menunjukkan nilai $P$-value yaitu 0,130 atau lebih besar dari 0,05 $(0,130>0,05)$. Tidak terdapat perbedaan yang nyata jumlah hasil tangkapan pada bulan Maret dan bulan April 2013. Komposisi hasil tangkapan nelayan di perairan Desa Selayar, Kabupaten Maluku Tenggara dapat dilihat pada Tabel 1 .

Berdasarkan komposisi hasil tangkapan nelayan, ikan yang dominan tertangkap adalah ikan layang dan dominan tertangkap selanjutnya ikan lemuru, selar, lencam dan biji nangka. Hal ini sesuai dengan informasi yang diperoleh dari nelayan bahwa musim penangkapan ikan terjadi sekitar bulan Maret sampai bulan Oktober dan puncaknya pada bulan September.

Ditinjau dari komposisi jenis berdasarkan alat tangkap maka perbedaan alat tangkap dan metode pengoperasian mempengaruhi komposisi jenis ikan yang tertangkap. Pengoperasian bagan pada malam hari di lapisan permukaan dengan alat bantu lampu hanya efektif menangkap dua spesies yaitu $D$. russeli dan Sardinella longiceps. Begitu pula dengan jaring insang yang dioperasikan pada siang hingga sore hari di lapisan permukaan, menyebabkan jaring insang hanya menangkap dua spesies ikan hal ini diduga bahwa pada siang hari 

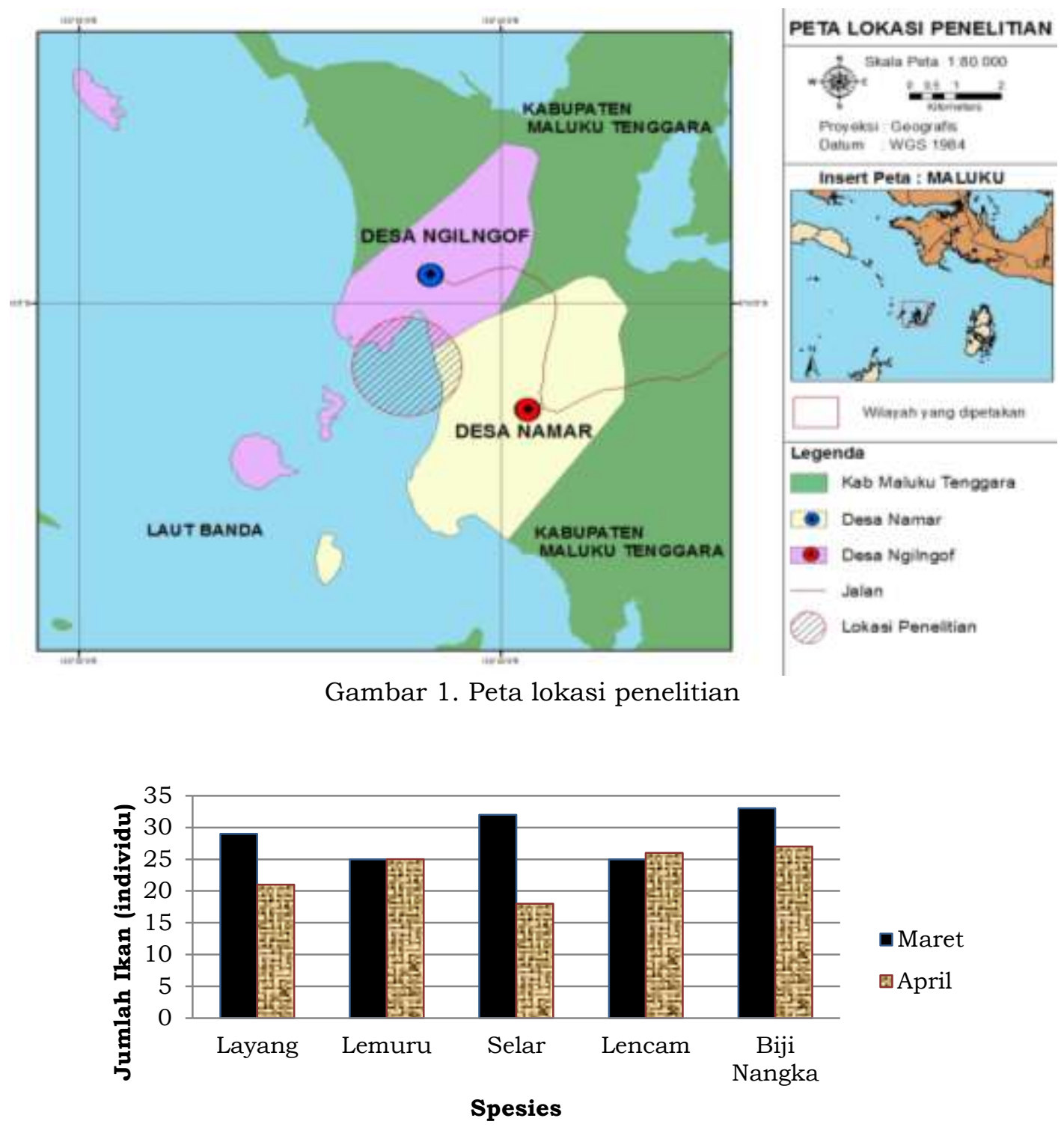

Gambar 2. Jumlah hasil tangkapan pada bulan Maret dan bulan April 2013

S. Crumenopthalmus dan Lethrinus lentjan menyebar dilapisan permukaan perairan secara lebih merata, sedangkan pada malam hari $D$. ruselli cenderung turun ke lapisan yang lebih dalam.

Ditinjau dari komposisi jenis berdasarkan alat tangkap maka perbedaan alat tangkap dan metode pengoperasian mempengaruhi komposisi jenis ikan yang tertangkap. Pengoperasian bagan pada malam hari di lapisan permukaan dengan alat bantu lampu hanya efektif menangkap dua spesies yaitu $D$. russeli dan Sardinella longiceps. Begitu pula dengan jaring insang yang dioperasikan pada siang hingga sore hari dilapisan permukaan, menyebabkan jaring insang hanya menangkap dua spesies ikan hal ini diduga bahwa pada siang hari $S$.
Crumenopthalmus dan Lethrinus lentjan menyebar di lapisan permukaan perairan secara lebih merata, sedangkan pada malam hari $D$. ruselli cenderung turun ke lapisan yang lebih dalam.

\subsection{Perbandingan Panjang dan Berat Ikan}

Hubungan panjang dan berat ikan hasil tangkapan menggunakan metode hubungan panjang berat untuk mengetahui pola pertumbuhan ikan di perairan Desa Selayar Kabupaten Maluku Tenggara.

Hasil analisis ikan layang, lemuru, selar, lencam dan biji nangka panjang dapat dilihat pada Tabel 1. Hasil analisis diketahui bahwa persamaan hubungan panjang dan berat ikan layang selama 
penelitian adalah $\mathrm{W}=7,901$ dengan kisaran nilai $b=4,803$, pada ikan lemuru nilai $b=3,209$, ikan selar nilai $b=2,191$, ikan lencam nilai $b=3,032$, dan ikan biji nangka nilai $b=2,495$. Nilai $b$ yang diperoleh dan setelah dilakukan uji $t$ $(a=0,05)$ terhadap nilai $b$ tersebut diketahui bahwa ikan layang, lemuru dan lencam memiliki pola pertumbuhan alometrik positif artinya pertambahan berat relatif lebih besar daripada pertambahan panjang atau $b>3$ (Effendie, 1997). Pola pertumbuhan yang berbeda terdapat pada ikan selar dan biji nangka dengan nilai $b<3$ artinya alometrik negatif yaitu pertambahan panjang lebih cepat dari pertambahan berat. Panjang total tertinggi ikan lemuru adalah 19,8 $\mathrm{cm}$ dan panjang total terendah yaitu 14,5 $\mathrm{cm}$ dengan berat tertinggi 90 gram dan berat terendah 40 gram.

Ikan yang tertangkap selama penelitian memiliki ukuran panjang dan berat tubuh yang berbeda-beda. Nilai b ikan layang sebesar 4,803. Penelitian yang sama dilakukan oleh Manik (2009), yang menunjukkan korelasi antara panjang dengan berat pada setiap bulan sangat signifikan dimana nilai b hubungan panjang dan berat bulanan umumnya di atas nilai 3 , kecuali pada bulan Mei yaitu $b=3$. Hal ini menunjukan bahwa pertumbuhan ikan layang pada umumnya menyimpang dari hukum kubik (alometrik positif). Hasil penelitian yang lain dilakukan Lelono (2007) menjelaskan perbedaan nilai $b$ dapat disebabkan oleh musim, jenis kelamin, area, temperatur, fishing time, fishing vessel dan tersedianya makanan. Moutopoulos dan Stergiou (2007) menyatakan bahwa perbedaan nilai $b$ juga dapat disebabkan oleh perbedaan jumlah dan variasi ukuran ikan yang diamati.

\subsection{Komposisi Makanan Ikan}

Komposisi makanan ikan yang mengacu pada fraksi makanan penting, maka jenis-jenis ikan yang tertangkap dilokasi penelitian dapat diklasifikasikan dalam 2 (dua) kelompok yaitu: (1) ikan omnivora yang cenderung pemakan hewan (zooplankton) seperti ikan lemuru, selar, layang dan lencam; (2) ikan karnivora yang mengkonsumsi berbagai jenis ikan dan cephalopoda seperti pada ikan biji nangka. Komposisi makanan ikan dapat dilihat pada Tabel 2.

Bedasarkan hasil perhitungan indeks propenden (indeks bagian terbesar), maka ikan layang, lemuru, selar, lencam dan ikan biji nangka makanan utamanya yaitu krustasea, makanan pelengkapnya hancuran karang, sisik dan duri ikan. Makanan tambahan yaitu hancuran ikan dan bivalvia. Berdasarkan tingkat trofik pada umumnya ikan di lokasi penelitian ini bersifat omnivora yang cenderung pemakan hewan (zooplankton). Hal ini terlihat dari jenis makanan yang ada sebagai makanan utama yaitu krustasea (Tabel 3). Kesamaan jenis makanan ikan dominan lebih nyata terlihat dalam nilai jenis makanan yang dikonsumsi cukup besar. Nilai tersebut menunjukkan besarnya tingkat pemanfaatan bersama dari populasi ikan terhadap sumberdaya makanan di perairan dan hal ini terjadi diduga karena kesamaan tingkat kebutuhan dalam pemenuhan nutrisinya.

Hasil penelitian di Sibolga menunjukan bahwa 85\% - 95\% terdiri dari krustasea, moluska (larva pelecypoda dan gastropoda), Riama (2000). Hasil yang sama ditemukan pada penelitian Ristiani (2012) menunjukan bahwa makanan utama dari ikan lencam adalah potongan Malacostraca dari Filum Crustacea.

Tabel 1. Komposisi hasil tangkapan nelayan diperairan Desa Selayar, Kabupaten Maluku Tenggara

\begin{tabular}{clllccr}
\hline \multirow{2}{*}{ No. } & \multicolumn{1}{c}{$\begin{array}{c}\text { Nama } \\
\text { Umum }\end{array}$} & \multicolumn{1}{c}{ Spesies } & Famili & $\begin{array}{c}\text { Jumlah } \\
\text { (individu) }\end{array}$ & $\begin{array}{c}\text { Panjang Total } \\
\pm \text { SD (cm) }\end{array}$ & $\begin{array}{c}\text { Berat } \pm \\
\text { SD (gr) }\end{array}$ \\
\hline 1 & Layang & Decapterus russeli & Carangidae & 50 & $12,5 \pm 18,2$ & $38 \pm 90$ \\
2 & Lemuru & Sardinella longiceps & Clupeidae & 50 & $13,3 \pm 19,8$ & $28 \pm 81$ \\
3 & Selar & S. crumenopthalmus & Carangidae & 50 & $14,2 \pm 21,9$ & $40 \pm 89$ \\
4 & Lencam & Lethrinus lentjan & Lethrinidae & 51 & $13,3 \pm 20$ & $28 \pm 92$ \\
5 & Biji nangka & $\begin{array}{l}\text { Upeneus } \\
\text { muluccensis }\end{array}$ & Mullidae & 60 & $14,2 \pm 21,9$ & $30 \pm 90$ \\
\hline
\end{tabular}


Tabel 2. Komposisi makanan ikan berdasarkan jenis alat tangkap dan tingkat trofik di perairan

\begin{tabular}{|c|c|c|c|c|c|c|c|}
\hline \multirow[b]{2}{*}{ No. } & \multirow[b]{2}{*}{ Jenis Ikan } & \multirow{2}{*}{$\begin{array}{c}\text { Alat } \\
\text { Tangkap }\end{array}$} & \multicolumn{5}{|c|}{ Jenis Makanan (\%) } \\
\hline & & & H. Ikan & Krustasea & H. karang & bivalvia & $\begin{array}{l}\text { Sisik dan } \\
\text { Duri }\end{array}$ \\
\hline 1 & Layang & Bagan & $7,44^{* *}$ & $56,68^{*}$ & $15,85^{* *}$ & $5,69^{* * *}$ & $14,37^{* *}$ \\
\hline 2 & Lemuru & Bagan & $2,85^{* * *}$ & $49,92^{*}$ & $12,78^{* *}$ & - & $34,45^{* *}$ \\
\hline 3 & Selar & $\begin{array}{l}\text { Jaring } \\
\text { Insang }\end{array}$ & $21,41^{* *}$ & $45,85^{*}$ & $18,32^{* *}$ & - & $14,40 * *$ \\
\hline 4 & Lencam & $\begin{array}{l}\text { Jaring } \\
\text { Insang }\end{array}$ & $9,28^{* *}$ & $47,48^{*}$ & $26,84^{* *}$ & $4,60^{* * *}$ & $11,78^{* *}$ \\
\hline 5 & Biji Nangka & Pancing & - & $60,09^{*}$ & $17,09 * *$ & - & $22,80^{* *}$ \\
\hline
\end{tabular}

\footnotetext{
Keterangan: * Makanan utama. ** Makanan pelengkap. *** Makanan tambahan $\mathrm{H}=$ Hancuran

Kriteria : IP $>25 \% \quad$ : makanan utama

$5 \% \leq \mathrm{IP} \geq 25 \%$ : makanan pelengkap

IP $<5 \% \quad:$ makanan tambahan
}

Tabel 3. Hasil tangkapan nelayan menurut alat tangkap, jenis ikan dan trofik level di Desa Selayar, Kabupaten Maluku Tenggara

\begin{tabular}{ccccccc}
\hline No. & $\begin{array}{c}\text { Nama } \\
\text { Umum }\end{array}$ & $\begin{array}{c}\text { PanjangTotal } \pm \text { S } \\
\mathrm{D}(\mathrm{cm})\end{array}$ & $\begin{array}{c}\text { Nilai Trofik } \\
\text { Level }\end{array}$ & $\begin{array}{c}\text { Jenis Alat } \\
\text { Tangkap }\end{array}$ & $\begin{array}{c}\text { Trofik } \\
\text { Level * }\end{array}$ & Ket ** \\
\hline 1 & Layang & $12,5 \pm 18,2$ & 3,38 & Bagan & $3,69-3,70$ & TL3 \\
2 & Lemuru & $13,3 \pm 19,8$ & 3,25 & Bagan & 3,0 & TL3 \\
3 & Selar & $14,2 \pm 21,9$ & 3,52 & $\begin{array}{c}\text { Jaring } \\
\text { Insang }\end{array}$ & $3,40-3,53$ & TL3 \\
4 & Lencam & $13,3 \pm 20$ & 3,64 & $\begin{array}{c}\text { Jaring } \\
\text { insang }\end{array}$ & $3,50-3,78$ & TL3 \\
5 & Biji nangka & $14,2 \pm 21,9$ & 4,03 & Pancing & $3,50-3,90$ & TL5 \\
\hline
\end{tabular}

Keterangan :**Klasifikasi trofik level menurut Stergiou et al, (2007)

*Nilai menurut metadata Fishbase (Froese dan Pauly, 2013)

Hal ini juga ditemukan pada metadata Fishbase (Froese dan Pauly 2013) yang menunjukkan bahwa ikan lencam di perairan Australia adalah bentos, Crustacea dan nekton. Hasil penelitian yang dilakukan oleh Susilawati (2001) menunjukan bahwa makanan utama ikan biji nangka yaitu udang-udangan, ikan kecil, detritus, polychaeta, molusca, Nitzehiasp, Ceratium sp dan Copepoda.

\subsection{Trofik Level Hasil Tangkapan}

Analisis tingkat trofik hasilnya menunjukkan bahwa lima spesies ikan yang tertangkap berada pada TL3 dan TL5. Spesies-spesies pada TL3 yaitu ikan layang, lemuru, selar, dan lencam, sedangkan pada TL5 yaitu ikan biji nangka. Nilai trofik level dapat disajikan pada Tabel 3. Trofik level setiap jenis ikan menunjukkan bahwa rata-rata ikan yang tertangkap oleh nelayan memiliki nilai trofik level antara 3 sampai dengan 5 dapat dilihat pada Gambar 3.

Mengacu pada komposisi berat hasil tangkapan (Gambar 4) maka diketahui bahwa komposisi biomassa ikan omnivora dan karnivora tidak seimbang dengan persentase total hasil tangkapan dihitung berdasarkan trofik level maka didapatkan bahwa persentase ikan pada trofik level 3 dan 5 secara berurut adalah $69 \%$ dan $31 \%$. Grafik trofik level dan biomassa hasil tangkapan setiap kelompok TL yang tertangkap di perairan Desa Selayar dapat dilihat pada Gambar 4.

Hasil tangkapan berdasarkan alat tangkap bagan dan jaring banyak menangkap jenis ikan dengan trofik level 3 $(2,9$ sampai 3,7$)$ yaitu omnivora yang cenderung pemakan hewan (zooplank- 
ton). Alat tangkap pancing hanya menangkap jenis ikan dengan trofik level 5 (4,0 sampai 4,5) yaitu karnivora yang cenderung pemakan ikan dan cephalopoda. Tingkat trofik ikan di perairan Desa Selayar menunjukan bahwa sebagian besar ikan dominan adalah omnivora (zooplanktivora) dengan nilai trofik berada pada trofik level 3. Kisaran nilai tersebut menunjukkan bahwa ikan dominan di perairan berada pada tingkat trofik rendah. Semakin rendah nilai tersebut maka semakin kecil energi yang dibutuhkan oleh ikan dominan untuk memperoleh makanannya dan tidak dapat tumbuh dengan jumlah yang lebih banyak.

Hasil tangkapan yang tidak seimbang antar kedua trofik level mengindikasikan bahwa kondisi ekologis kedua ekosistem di perairan Desa Selayar dilihat dari trofik level ikan yang tertangkap dengan bagan, jaring insang dan pancing relatif merusak ekosistem.
Masih rendahnya proporsi ikan karnivora pada trofik level 5 khususnya ikan biji nangka merupakan indikator penting bahwa rantai makanan (food chain) kurang baik dan tidak mendukung untuk pertumbuhan dan kelangsungan hidup ikan-ikan pada trofik level lebih tinggi. Berbeda dengan hasil panalitian Asriyana (2011), yang mendapatkan proporsi trofik level ikan karnivora yang tertangkap dengan alat tangkap sero sangat tinggi di Perairan Teluk Kendari yang menunjukkan bahwa tidak terjadi overfishing di wilayah tersebut.

Hasil penelitian menunjukkan bahwa ikan hasil tangkapan dilokasi penelitian pada alat tangkap bagan dan jaring insang memiliki dampak penangkapan yang lebih besar TL3 (ikan layang, lemuru, selar dan lencam)dibandingkan alat tangkap pancing TL5 (seperti ikan biji nangka) sehingga akan menyebabkan struktur komunitas ikan menjadi berubah dan piramida menjadi tidak stabil.

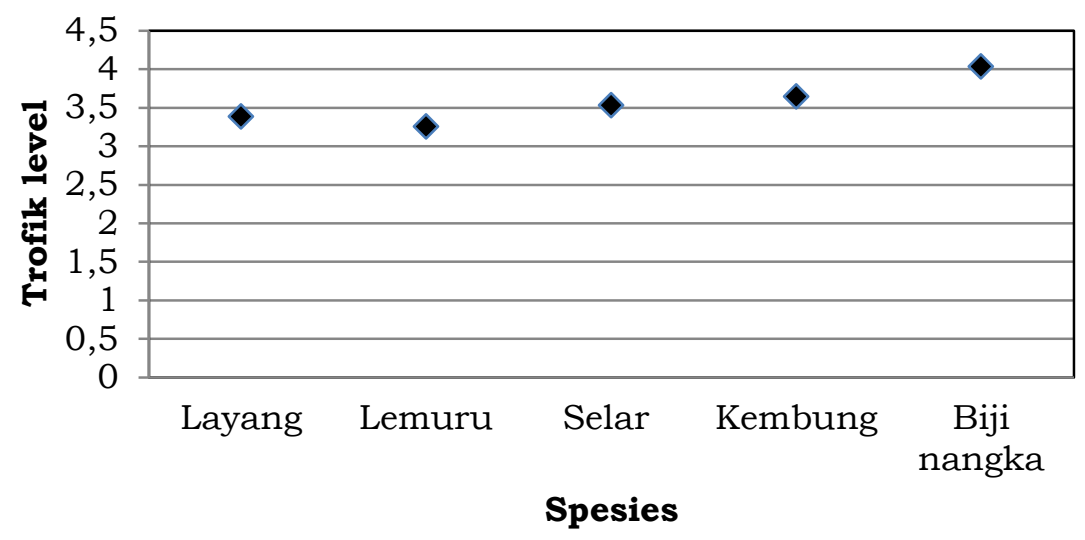

Gambar 3. Trofik level hasil tangkapan setiap jenis ikan yang tertangkap pada lokasi penelitian

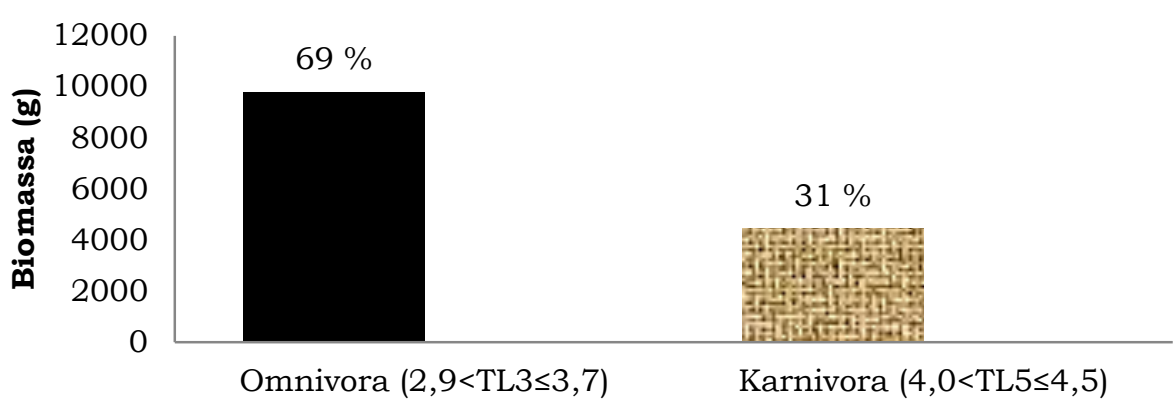

Trofik Level

Gambar 4.Grafik trofik level dan biomassa hasil tangkapan setiap kelompok TL yang tertangkap di perairan Desa Selayar 
Menurut Cury et al (2003) kondisi TL3 termasuk kedalam wasp-waist control dimana hasil tangkapan lebih banyak pada TL3 sehingga penurunan komposisi pada TL4 dan TL5 sedangkan pada TL1 menunjukan penurunan komposisi ikan namun pada TL2 berpotensi meningkat.

\section{KESIMPULAN}

Hasil tangkapan oleh bagan, jaring insang dan pancing mengindikasikan bahwa terjadi eksploitasi yang tidak seimbang pada rantai makanan. Kelompok TL3 dan TL5 lebih dominan dieksploitasi dan berpotensi merusak keseimbangan ekologis sumberdaya ikan di perairan. Alat tangkap bangan dan jaring mempunyai dampak lebih besar terhadap keberlanjutan sumberdaya ikan dibandingkan dengan alat tangkap pancing, karena kedua alat tangkap tersebut cenderung lebih eksploitatif pada ukuran ikan yang belum layak tangkap.

Perlu adanya penelitian lanjutan yang menganalisis feeding guilds pada setiap musim penangkapan dengan berbagai jenis alat tangkap. Berbagai alat tangkap dan metode penangkapan perlu diterapkan untuk memperoleh data yang lebih baik namun penangkapan untuk memperoleh hasil tangkapan harus memperhatikan prinsip-prinsip ekologis agar tidak berpotensi merusak keseimbangan ekologi pada perairan.

\section{DAFTAR PUSTAKA}

Asriyana 2011. Interaksi Trofik Komunitas Ikan sebagai Dasar Pengelolaan Sumberdaya Ikan di Perairan Teluk Kendari. Sulawesi Tenggara. (Tesis). Bogor (IDN): Fakultas Perikanan dan Ilmu Kelautan, Institut Pertanian Bogor.

Effendie MI. 1997. Biologi Perikanan. Yogyakarta (ID): Yayasan Pustaka Nusatama.

Froese R, Pauly D (editors). 2013. FishBase. World Wide Web electronic publication. www. Fishbase.

Lelono TD. 2007. Dinamika populasi dan biologi ikan lemuru (Sardinellalemuru) yang tertangkap dengan purse seine di Pelabuhan Perikanan Nusantara Prigi Trenggalek, p.1-11. In: Isnansetyo A, Murwantoko, Yusuf IBL, Djumanto, Saksono H, Dewi IP, Setyobudi E, Soeparno, Prabasunu N, Budhiyanti SA, Ekantari N, Ptiyono SB (editor).

McClanahan T R, S Mangi. 2004. Gearbased management of a tropical artisanal fishery based on species selectivity and capture size. Fisheries Management and Ecology 11:51-60.

Riama 2000. Aspek Biologi Reproduksi dan Pertumbuhan Ikan Lemuru di Perairn Teluk Sibolga, Sumatra Utara. [Skripsi]. Fakultas Perikanan dan Ilmu Kelautan, Institut Pertanian Bogor.

Ristiani 2012. Dampak Penangkapan Ikan Terhadap Keseimbangan Trofik Level Pada Habitat Lamun Di Kepulauan Seribu, Provinsi Dki Jakarta. (Skripsi). Bogor (ID). Fakultas Perikanan dan Ilmu Kelautan, Institut Pertanian Bogor.

Stergiou KI, Moutopoulus DK, Casal HJA dan Erzini K. 2007. Trophic Signatures of Small-Scale Fishing Gears: Implications for Conservation and Management. Marine Ecology Progress Series. No. 333: 117-128.

Sulistiono. 2004. Kebiasaan Makanan Ikan Buntal Pisang (Tetraodon Lunaris) di Perairan Mayangan, Jawabarat. Jurnal Iktiologi Indonesia, Vol. 4, No 1, Juni.

\section{UCAPAN TERIMA KASIH}

Ucapan terimakasih penulis sampaikan kepada Politeknik Perikanan Negeri Tual yang telah memberikan ijin kepada penulis untuk menggunakan Laboratorium, menganalisis isi lambung ikan, dan kepada Prof Dr Ir Mulyonos S Baskoro, Dr Roza Yusfiandayani dan Dr Am Azbas Taurusman, yang telah memberikan bimbingan dan motivasi kepada penulis. Tidak lupa, terimakasih juga penulis sampaikan kepada semua pihak yang telah berpartisipasi dalam penyelesaian tulisan ini. 